\section{At the click of a button}

\author{
S Hancocks, OBE*
}

\section{... and if I click this button? The wonder of practice computerisation has been with us for some time and so now is the remarkable opportunity to have a practice website. Oh dear!}

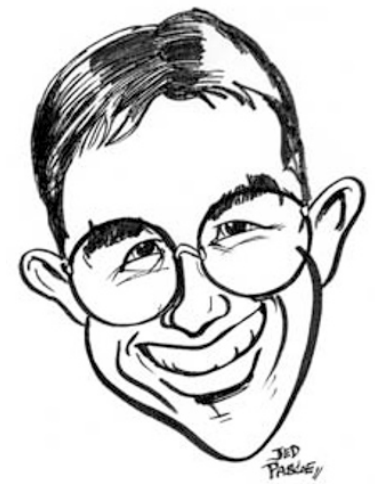

There is a fair chance that you thought you'd get away with it. With not having to get involved with computers before you retired, let alone have to deal with websites. How wrong could you have been?

Fill a bucket with clichés and, guaranteed, the one floating right on the top would read 'technology moves so fast nowadays'. Because it does. How could the redoubtable Mr Logie Baird possibly have known what he was letting us all in for as he squinted at the blue flickering rays of his gassy vacuum chamber? Even the description 'cathode ray tube' has a museum-like twinge of nostalgia that the hardest hearted amongst us can't entirely resist. It was only a handful of years ago that in order to work your 'micro' it was necessary to know complex electronic syntax such as 'if A string equals $B$ then print $C$ '. Not to mention a definite need to recognise whether or not you were conversing in PASCAL or ERASMUS or some such.

It was certainly at this stage, when, closeted away with my delightfully rubberkeyed Spectrum ZX (anyone else out there remember how deliciously comforting to the finger tips rubber keys were?) I thought that perhaps, just perhaps, I could reach retirement without having to fully grasp exactly what 'if A string equals...' was all about. At similar lightning pace arrived the mysteries of the Internet. But each new turn of history brings its plusses and minuses, and how happy that as a by-product, the '@' key has at last come into its own. For decades relegated to being used only for primary level maths sheets such as 'If I buy three buns@ @20 each how much change would I expect from $\mathfrak{E} 1$ ?', the @ key is frequently now the one that wears out most quickly, evidencing that tell tale dip so familiar of stone steps in ancient monasteries and English Public schools.

So, having computerised the practice, the next challenge is to create a practice website. It is the sort of item that arises from a staff meeting, or a brainstorm or, in the most contemporary of practices, a 'retreat' at some Welsh outward-bound centre. 'What about a website?' some bright den- tal-team spark asks and everyone else, not wanting to appear totally twentieth century, immediately takes up the chant, website, website, website.

Fortunately a friend of the receptionist's brother is seemingly a bit of a whizz at designing websites and so plans are laid to ask him to generate an electronic portal fit for the likes of Moonside Dental Centre. Unlike the revolution, which has moved us

\section{Entering the site, the} viewer sweeps down, as if from the moon, into the earth's atmosphere and straight into your own street, narrowly Way bus depot, before alighting... at reception.

on from bakelite radios to microwaves that cook chips on railway station platforms in the twinkling of an atomic particle, designing web sites can, it appears, not be rushed.

Lots of important things have to be considered, many of which have baffling abbreviations like HTMLs and URLs and then there are things like considering hyperlink resolution interfaces. Hmm! Sooner or later you assume that something will happen to enable your patients to zap straight into your electron-friendly practice. In your mind's eye it will have all sorts of lovely 'click' options, like, 'please click here if you'd like to take up the never ending benefit of private perio treatment' (your personal favourite) or 'here if you would like to set up a direct debit option for all your future implant and complex restoraavoiding the Canal tive treatment requirements'. However, when Bob, the receptionist's brother's friend who knows all about these things turns up with the demonstration it isn't quite as clear cut as you had hoped.

Used to dealing with websites for large industrial concerns, Bob has come up with something of a monolithic opening page based on a rock face crumbling in the wake of a giant and rather alarmingly realistic detonation. This then reveals a panorama of 'buttons', on which your erstwhile patients are supposed to click, in the form of luridly coloured graphics of newly extracted molars. A diplomatic and not inconsiderable briefing about trying to improve the image of dentistry follows, before Bob comes back with his next best shot.

Admittedly, Moonside Dental Centre looks good as, entering the site, the viewer sweeps down, as if from the moon, into the earth's atmosphere and straight into your own street, narrowly avoiding the Canal Way bus depot, before alighting in blissful wonderment at reception. And what a boon was that virtual reality version of Happy Receptionist Tracy? What new patient could have resisted, as she leant across the counter and pressed an orchid of arrival into their hand? Then again you had qualms about the whole truthfulness thing of this particular image. Especially as you don't give out orchids and the non-virtual reality that is Slightly Grumpy Tracy is more likely to take a swing with the waiting room rubber plant at the slightest hint of sarcasm from a passing patient.

All in all, you take a deep breath and decide that, just like creating the practice logo and designing the atrium that houses the autoclave suite, there is no substitute for a professional. So you check out web designers on the 'net' so that your patients can discover exactly what happens if they click the button.

Technology? Marv-e-llous.

${ }^{*}$ The author is commissioning editor for the $\mathrm{BDJ}$. 